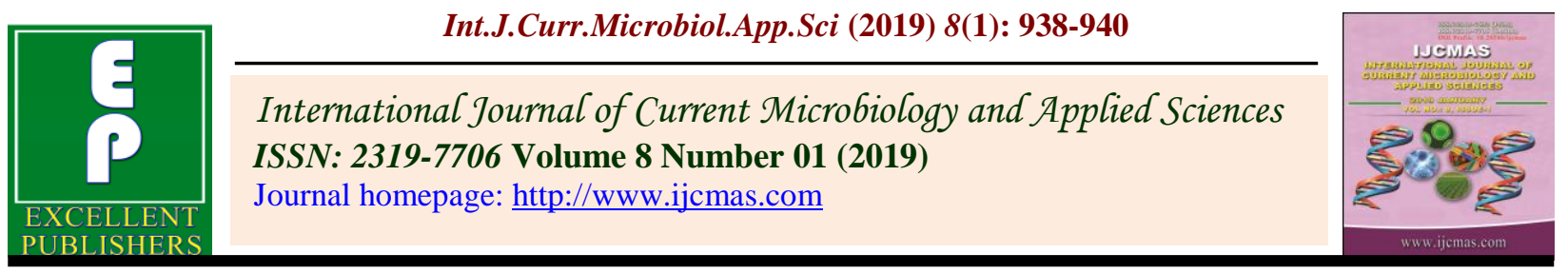

Case Study

https://doi.org/10.20546/ijcmas.2019.801.101

\title{
Infertility in a Crossbred Cattle as a Sequel to Uterine Form of Tuberculosis
}

\author{
S.S. Dhindsa ${ }^{1}$, Navgeet Singh ${ }^{1}$, Harmeet Singh ${ }^{1}$ and Bilawal Singh ${ }^{2}$ \\ ${ }^{1}$ Department of Veterinary Gynaecology and Obstetrics, ${ }^{2}$ Veterinary and Animal Husbandry \\ Extension Education, Guru Angad Dev Veterinary and Animal Sciences University, \\ Ludhiana, Punjab, India- 141001 \\ *Corresponding author
}

A B S T R A C T

Keywords

Crossbred cattle, Infertility, Tuberculosis, Tuberculin test, Ultrasonography

Article Info

Accepted:

10 December 2018

Available Online:

10 January 2019
The current report presents a rarest case of uterine tuberculosis in cattle. A seven years old crossbred cattle having completed two normal parities developed infertility, as it was not able to conceive after various attempts of artificial inseminations. The clinical parameters of animal were often reported in normal range over repeated examinations except for slight loss of condition. The cause of infertility was ascertained through a positive intradermal tuberculin test and presence of multiple raised nodules in both uterine horns appreciable upon ultrasonography.

\section{Introduction}

Infertility in female animals refers to inability to conceive even after repeated inseminations with fertile semen. The causes of infertility in cattle are numerous and complex (Singh et al., 2017).

It may either be due to non-infectious causes such as poor management, improper nutrition and hormonal disturbances, or infectious causes including pyometra, endometritis and various bacterial, viral, mycotic as well as protozoal infections (Drillich et al., 2005).
Sometimes, idiopathic abortions are also considered as a form of infertility.

Although, all the above listed causes have been found associated with infertility, functional infertility is reported to be more common than infertility due to infectious diseases among cattle in India (Singh et al., 1981). The causes of infertility must be identified and eliminated for success of dairy farming in the country (Kumar et al., 2016). Thus, the present communication reports a rare instance of infertility in a crossbred cattle due to uterine form of tuberculosis. 


\section{History and Observations}

A regular cyclic crossbred cattle in the $3^{\text {rd }}$ lactation was presented with the chief complaint of repeat breeding, as it was not able to conceive after four attempts of artificial inseminations over a period of one year. The animal was regularly fed high quality ration and mineral mixture as per nutritional recommendations and treated for clinical endometritis thrice with broad spectrum antibiotics. The cow had been vaccinated against various diseases and dewormed against internal as well as external parasites time to time. All the basic clinical parameters of animal such as respiration, pulse, temperature etc. were often reported to be normal over repeated examinations. Reportedly, there was slight loss of condition over a period of time even after having normal appetite suggesting some chronic debilitating condition such as tuberculosis. Per-rectal examination revealed normal gross appearance, shape and size of genitalia. Keeping all these observations in view, it was decided to perform intradermal tuberculin test to confirm tuberculosis and transrectal ultrasonography to get in depth details about genitalia.

\section{Results and Discussion}

The animal was found positive for tuberculosis upon complementary intradermal testing $(0.1 \mathrm{ml}$ bovine tuberculin PPD 3000 IU; $0.1 \mathrm{ml}$ avian tuberculin PPD $2500 \mathrm{IU}$, PRIONICS), however, there was no evidence of visibly enlarged lymph nodes and respiratory signs pertaining to pulmonary form of tuberculosis. This was suggestive of tuberculosis being extra pulmonary. Transrectal ultrasonography of genitalia revealed multiple raised nodules in endometrium of both the uterine horns (Fig. 1) with otherwise normal ovaries. This ultrasonographical finding gave a good evidence that animal was having uterine form of tuberculosis. There is no recommended treatment of tuberculosis in bovines and the best control policy is to test and slaughter the infected animals.

Fig.1 Arrows pointing towards the multiple raised nodules in endometrium of left and right uterine horns (Cross sectional view), respectively
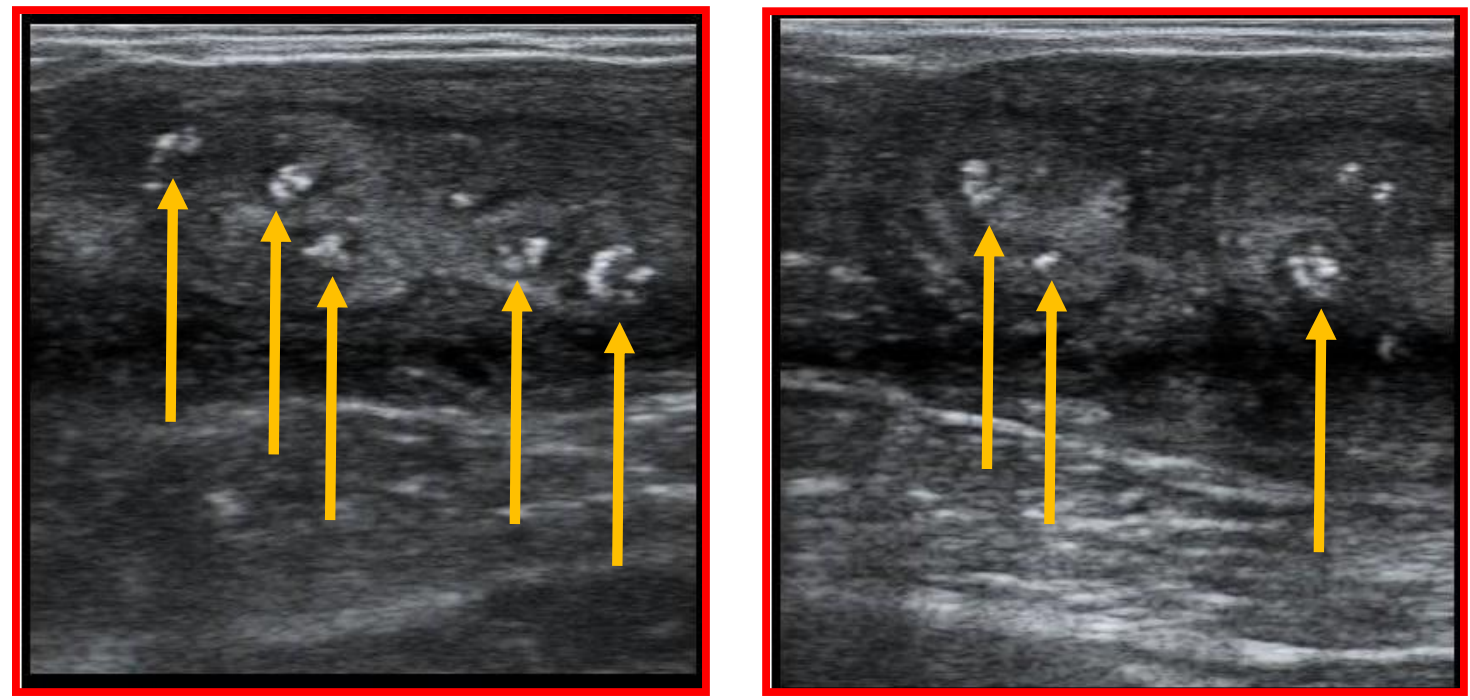
Bovine tuberculosis is widespread throughout most of the world including India (Vegad, 2005). It is generally a chronic debilitating disease and early infections are often asymptomatic. In bovine with extensive miliary tubercular lesions, a progressive loss of condition in the absence of other clinical signs may be the only observable sign. Occasionally, uterine tuberculosis may develop which result in infertility or recurrent abortion following conception. Clinical signs may further include mucopurulent discharges, vulvar discharges and placentitis if animal becomes pregnant. Irregular estrus may also be observed in some cases of uterine tuberculosis. Mycobacterium tuberculosis was isolated by Mohanty et al., (1980) from a Hariana heifer that was a chronic repeat breeder. Although, only histopathology can provide a confirmatory diagnosis of uterine form of tuberculosis which could not be achieved in the present case because the animal was alive and genitalia can only be recovered at necropsy once the animal dies naturally, but still the results of intradermal tuberculin test and rectal ultrasonography provide a fair evidence of this ailment. Thus, the present ultrasonographical findings may assist the veterinarians to promptly establish the cause of bovine infertility and to plan future course of action in such cases.

\section{References}

Drillich, M., Raab, D., Wittke, M., and Heuwieser, W. 2005. Treatment of chronic endometritis in dairy cows with an intrauterine application of enzymes. A field trial. Theriogenology 15: 18111823.

Kumar, A., Bhakar, S.K., Sharma, N., and Hemlata. 2016. The effect of cloprostinol on persistent corpus luteum in cattle. Vet. Pract. 17(2): 231-232.

Mohanty, B.N., Parihar, N.S., and Luktude, S.N. 1980. Tuberculosis of genital organs causing repeat breeding in cattle. Indian Vet. J. 57: 859-860.

Singh, C.S.P., Singh, S.K., and Singh, B. 1981. Studies on the incidence of infertility in cows. Indian Vet. J. 58: 909-912.

Singh, M., Sharma, A., Sharma, A., and Kumar, P. 2017. Repeat breeding and its treatment in dairy cattle of Himachal Pradesh (India) - A review. Indian J. Anim. Reprod. 38(2): 1-5.

Vegad, J.L., and Katiyar, A.K. 2005. A textbook of veterinary special pathology. $1^{\text {st }}$ edition. CBS Publishers and Distributors Pvt. Ltd., New Delhi, India. pp 356.

\section{How to cite this article:}

Dhindsa, S.S., Navgeet Singh, Harmeet Singh and Bilawal Singh. 2019. Infertility in a Crossbred Cattle as a Sequel to Uterine form of Tuberculosis. Int.J.Curr.Microbiol.App.Sci. 8(01): 938-940. doi: https://doi.org/10.20546/ijcmas.2019.801.101 